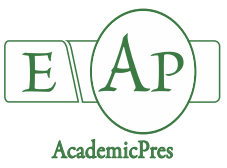

Eksi S et al. (2020)

Notulae Botanicae Horti Agrobotanici Cluj-Napoca 48(1):66-78

DOI:10.15835/nbha48111736

Research Article



\title{
Determination of the antimicrobial and antibiofilm effects and 'Quorum Sensing' inhibition potentials of Castanea sativa Mill. extracts
}

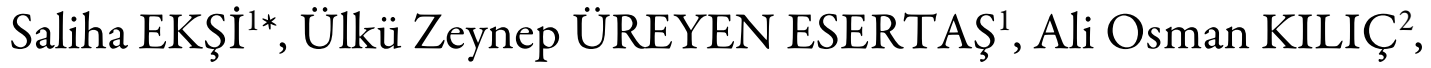 Nebahat EJDER ${ }^{1}$, Barış UZUNOK ${ }^{3}$}

\author{
${ }^{1}$ Recep Tayyip Erdoğan University, The Faculty of Medicine, Department of Medical Microbiology, 53020 Rize, \\ Turkey; saliha.eksi@erdogan.edu.tr(*correspondingauthor);biyolog_ulku@hotmail.com;nebahat.aydogan@erdogan.edu.tr \\ ${ }^{2}$ Karadeniz Technical University, Faculty of Medicine, Department of Medical Microbiology, 61080 Trabzon, Turkey; akilic@ktu.edu.tr \\ ${ }^{3} U_{s}$ ak University, Faculty of Medicine, Department of Physiology, $64300 U_{s}$ sak, Turkey; Uzunok20@yahoo.com
}

\begin{abstract}
The rapid rise of resistance causes existing antibiotics to become dysfunctional. Therefore, search for new antimicrobial active ingredients has increased in recent years. In this study, flower extracts of Castanea sativa were examined for antimicrobial and anti-quorum sensing aspects. The antimicrobial properties of methanol, ethyl acetate, ethanol and hexane extracts of $C$. sativa against some gram-positive and gram-negative bacterial species, as well as yeasts (Candida albicans and Candida parapsilosis) were investigated by the agar well diffusion method. The minimum inhibition concentration (MIC) and minimum bactericidal concentrations (MBC) of C. sativa extracts were also determined. Chromobacterium violaceum ATCC 12472, C. violaceum 35352, C. violaceum VIR07 and C. violaceum CV026 indicator strains were used for determination of the quorum sensing inhibitions, and the Pseudomonas aeruginosa PAO1 strain was used for the swarming tests. Additionally, biofilm inhibition was detected by the spectrophotometric method using the P. aeruginosa PAO1 strain. Methanol, ethanol and ethyl acetate extracts of $C$. sativa was found to have high antibacterial and antifungal effects, while the methanol extract also had anti-quorum sensing, anti- swarming and biofilm inhibition effects, but no activity was found in the n- hexane extract. To the best of our knowledge this is the first report revealed that methanol extract obtained from C. sativa flowers induced anti-quorum sensing activities mainly inhibited the violacein production, swarming and biofilm formation. The present investigation provided evidence that the $C$. sativa flower extract maybe a potential source of antimicrobial agents. Therefore, much attention should be paid to C. sativa flower content, which could be used with high efficacy against microorganisms.
\end{abstract}

Keywords: antimicrobial activity; biofilms; Castanea sativa; quorum sensing

Introduction

The effectiveness of current antibiotics on microorganisms has been decreasing rapidly in recent years. Moreover, it is obvious that antibiotic resistance will be one of the most important issues of the global agenda 
in the future as it is today. Antibiotic resistance is increasingly diminishing the options available for treatment of diseases and requires a search for new sources of treatment. As a result of this, interest in herbal resources in modern medicine is increasingly growing (Paul et al., 2010). In recent years, 22\% of all newly approved drug molecules have been synthesized as natural product derivatives (semi-synthetic), $4 \%$ were produced as real natural products, and $13 \%$ were produced as pharmacophore of a natural product (Newman and Cragg, 2012). C. sativa is known as sweet chestnut and is a plant belonging to the Fagaceae family. From the past to the present, it has been used in folk medicine to treat a wide range of diseases such as the common cold, diarrhea, asthma, bronchitis, heart, back pain and rheumatism. It was also used as a bleeding inhibitor due to the high tannin content in its shell (Lim, 2013).

Body of study has been done using different part of C. sativa. Hao et al. (2012) examined the antimicrobial activities of the shell, membrane and leaves of Japanese (Castanea crenata), European (Castanea sativa) and Chinese (Castanea mollissima) chestnuts. The results showed that the chestnut membrane had more antimicrobial compounds namely flavanol, glycosideand terpenoid than its leaf and shell parts.

A study conducted in 2010, showed that the extracts obtained from leaf, pericarp and aciculate peel of C. sativa had high antimicrobial activity (Zitkovic et al., 2010). Additionally, Spanish researchers characterized the compounds found in chestnut flowers, demonstrated their antioxidant potential and reported that it may be possible to extend the shelf life of products and reduce the consumption of chemical additives by coating foodstuffs with these molecules (Carocho et al., 2014). Furthermore, many scientific papers have reported the antimicrobial activities of honey which is one of the oldest traditional medicines considered to be important in human health (Mcloone et al., 2015). Even though a number of investigations suggested the antimicrobial properties of different honeys from around the world, very few studies have been done with chestnut honeys. Among those, Kolayli et al. (2016) reported that chestnut honeys had potent antimicrobial activities against $S$. aureus, E. coli E. faecalis, while no antifungal activity was recorded against Candida albicans and Candida cerevisiae. Moreover, another study carried out by Ronsisvalle et al. (2017) to evaluated antimicrobial activity of two different chestnut honeys. Interestingly, they they also found strong antimicrobial activity against $S$. aureus, E. coli and P. aeruginosa.

C. sativa is the only native species of genus Castanea grows in Europe and Turkey. This species has a distribution from the Eastern Black Sea to Mediterranean Regions in Turkey (Ketenoğlu et al., 2010). The leaves of C. sativa are used in the treatment of pertussis in the Kalkandere district of the province of Rize, while it is used as tea by the public in dyspnea and cardiovascular diseases in the Hayrat area of the province of Trabzon (Yaldiz et al., 2010). According to our research in the literature, there is not a sufficient number of scientific studies about the flower of $C$. sativa which is widely used in the region and utilized by the local people for the health benefits. These benefits have certainly close association to some of the bioactive secondary compounds. However, it was determined by the researchers that polyphenolic compounds (Pacheco-Ordaz et al., 2018) which have been reported to have antimicrobial effect in the literature are found in high percentage of the flower parts of C. sativa (Pereira et al., 2013; Vasconcelos et al., 2010). Therefore, this study investigated the effects of methanol, ethyl acetate, ethanol and hexane extracts obtained from the flowers of chestnut plant for the antimicrobial, anti-quorum sensing and biofilm inhibition properties.

\section{Materials and Methods}

\section{Collection of C. sativa plant and preparation of its extracts}

The flowers of $C$. sativa used in the study were collected from İkizdere (Rize, Turkey), cleaned and fresh flowers were stored at $-20^{\circ} \mathrm{C}$ until used. The extracts were obtained using methanol, ethyl acetate, ethanol and hexane by maceration method (Solanki and Nagori, 2012). Briefly, 10-20 g of the flower of chestnut stored at 
$-20{ }^{\circ} \mathrm{C}$ were weighed, ground into fine powder and mixed with 100 or $200 \mathrm{~mL}$ solvent. Extraction was conducted on a shaker at room temperature (RT) for $48 \mathrm{~h}$. After that, the extracts were filtered through filter paper and the solvents were evaporated in an evaporator (LabTech. EV311) at $40^{\circ} \mathrm{C}$. Subsequently, the extracts were suspended at $50-200 \mathrm{mg} / \mathrm{mL}$ in Dimethyl sulfoxide (DMSO) and aliquots of these were stored at $-20^{\circ} \mathrm{C}$ until needed for further assays. Pre-experimental working concentrations were diluted to $10 \mathrm{mg} / \mathrm{mL}$, and the concentrations to be used in the experiments were adjusted from these dilutions.

\section{Media and cultures conditions}

Bacteria and yeast strains used in the study are given in Table 1. The stocks cultures of the microorganisms were stored at $-80^{\circ} \mathrm{C}$. Before the experiment, Mycobacterium smegmatis strain was prepared by 3-day incubation in Brain Heart Infusion Agar (BHIA), Candida was prepared by 2-day incubation in potato dextrose agar (PDA), and finally other microorganisms were prepared by 1-day incubation in Mueller Hinton Agar (MHA). Stocks of the positive controls (ampicillin, gentamicin, ciprofloxacin and amphotericinB) were prepared at $200 \mu \mathrm{g} / \mathrm{mL}$ and aliquots stored at $-20^{\circ} \mathrm{C}$ for further antimicrobial testing. The necessary concentrations were added from these stocks during the experiments. As a negative control, the equivalent concentration to the extracts from DMSO was added to the corresponding wells.

Table 1. Microorganisms used for the antimicrobial activity

\begin{tabular}{|c|}
\hline Type of microorganism \\
\hline Staphylococcus aureus ATCC 25923 \\
\hline Escherichia coli ATCC 25922 \\
\hline Pseudomonas aeruginosa ATCC 27853 \\
\hline Bacillus subtilis ATCC 6633 \\
\hline Enterococcus faecalis ATCC 29212 \\
\hline Enterobacter aerogenes ATCC 13048 \\
\hline Acinetobacter haemolyticus ATCC 19002 \\
\hline Klebsiella pneumoniae ATCC 13883 \\
\hline Salmonella typhimurium ATCC 14028 \\
Candida albicans ATCC 10231 \\
\hline Candida parapsilosis ATCC 22019 \\
\hline Mycobacterium smegmatis ATCC 607 \\
\hline Chromobacterium violaceum ATCC 12472 \\
\hline Bacterial strains used in Quorum sensing inhibition tests \\
\hline Chromobacterium violaceum ATCC 12472 \\
\hline Chromobacterium violaceum ATCC 31352 \\
\hline Chromobacterium violaceum VIR07 \\
\hline Chromobacterium violaceum CVO26 \\
\hline Pseudomonas aeruginosa PAO1* \\
\hline
\end{tabular}

*It was used in the tests of 'Quorum Sensing' inhibition / Biofilm inhibition

\section{Determination of antimicrobial activity by the agar well diffusion method}

Agar diffusion method determination was performed according to Denev et al. (2014). Briefly, all the microorganisms were seeded in media as mentioned above. Following that bacteria cultures inoculated at 37 ${ }^{\circ} \mathrm{C}$. Meanwhile, Candida species were incubated at $35^{\circ} \mathrm{C}$. The density of $M$. smegmatis strain was adjusted to $0.5 \mathrm{McF}$ arland in BHIB (Woods et al., 2003), the density of the other microorganisms and Candida species were adjusted to 0.5 and $1.0 \mathrm{McF}$ arland in a Phosphate buffered saline solution (PBS), respectively. Following that, M. smegmatis strain was spread onto BHIA plates, the other test microorganisms were inoculated onto 
MHA plates and Candida species cultured onto MHA plates including 2\% glucose and $0.5 \mu \mathrm{g} / \mathrm{mL}$ methylene blue dye (CLSI, 2009). C. sativa extracts of $10 \mathrm{mg} / \mathrm{mL}$ concentration were prepared in 3\% DMSO. Wells with $6 \mathrm{~mm}$ diameter were punched on the agar media and each well filled with $50 \mu \mathrm{L}$ of the extracts from different solvents. The positive or negative controls were also added to the corresponding wells.

The cultures were incubated at $37^{\circ} \mathrm{C}$ for each microorganism at appropriate times, Candida species were incubated at $35^{\circ} \mathrm{C}$. the plates were examined visually for the formation of clear zone around the wells. The zone with a diameter greater than $6 \mathrm{~mm}$ were considered zones of inhibition.

\section{Determination of minimum inbibition concentration}

An extract having antimicrobial activity within the agar diffusion assay were further tested for the determination of the MIC (Minimum Inhibition Concentration) values. The microorganisms were incubated on the appropriate medium at appropriate times as indicated above. Subsequently, $0.5 \mathrm{McF}$ arland suspensions for bacteria cultures and 1.0 McFarland from Candida cultures were prepared into appropriate medium (RPMI 1640 (0.2\% glucose) for Candida species (CLSI, 2008), BHIB for $M$ smegmatis (Woods et al., 2003), and MHB-II for other microorganisms were used (CLSI, 2006; Murray et al., 2009).

Afterwards, $100 \mu \mathrm{L}$ respective medium for each microorganism was added to each well of the microplates. Subsequently, $100 \mu \mathrm{L}$ of $C$. sativa extracts from the $10 \mathrm{mg} / \mathrm{mL}$ stocks were added to the first wells of the plates. After positive controls (ampicillin, gentamicin, ciprofloxacin and Amphotericin-B) and negative control DMSO were applied into the corresponding wells, twofold dilutions were made. Next, $10^{6} \mathrm{CFU} / \mathrm{mL}$ bacteria to be tested were added to the respective wells and the microplates were incubated at $37^{\circ} \mathrm{C}$ for the relevant times for each microorganism. Each assay was performed in duplicate and repeated at least two times. The MIC was determined as the lowest concentration which showed no bacterial growth.

\section{Determination of minimum bactericidal concentration values}

To determine the minimum bactericidal concentration (MBC), $50 \mu \mathrm{L}$ samples were taken out from the MIC well and the previous three wells and they were seeded onto the plates with relevant media and left to incubated at $37^{\circ} \mathrm{C}$ for the relevant times for each microorganism. After evaluating the reproduction in Petri dishes, $\mathrm{MBC}$ was defined as the lowest concentration at which no viable cell growth on the plate (NCCLS, 1999).

\section{Determination of anti-quorum sensing}

To test anti-quorum sensing; all extracts were used for violacein inhibition assay, but only the methanol extract was used to determine the swarming and biofilm tests since it induced the high antimicrobial effect by the agar well diffusion method.

\section{Determination of violacein inbibition}

In order to determine pigment inhibition, after determining the Sub-MIC values of the strains of $C$. violaceum ATCC 12472, C. violaceum 35352, C. violaceum VIR07 and C. violaceum CV026 as above, Chromobacterium species were inoculated in $5 \mathrm{~mL} \mathrm{LB}$, and overnight cultures were prepared in a shaking incubator at $37^{\circ} \mathrm{C}$.

On the following day, the cultures were adjusted to $0.5 \mathrm{McF}$ arland in PBS and the signaling molecules used for indicator strains were prepared in DMSO and ethyl acetate separately in the concentrations of C6AHL $2 \mathrm{mg} / \mathrm{mL}$, C7-AHL $2.1 \mathrm{mg} / \mathrm{mL}$ and C12-AHL $2.8 \mathrm{mg} / \mathrm{mL}$ (Torres et al., 2013). Subsequently, $50 \mu \mathrm{L}$ of each culture was inoculated into $5 \mathrm{~mL}$ of soft LB agar, and among the indicator strains, C6-AHL and C7-AHL were added for CV026, and C12-AHL $25 \mu \mathrm{L}(1 \mathrm{mM})$ was added for VIR07. These cultures were poured onto $\mathrm{LB}$ agar plates and left to dry, then $50 \mu \mathrm{L}$ of the determined Sub-Mic concentrations of each extract were added to the opened wells. As a result, the presence of anti-quorum sensing was determined by evaluating the zones 
where the continuity of bacterial growth seen but the formation of purple pigment was suppressed (McLean $e t$ al., 2004; Koh and Tham, 2011).

Additionally, the methanol extract which was effective on all Chromobacterium by the agar well diffusion method was also evaluated spectrophotometrically. The Sub-Mic and sub-concentrations of the extract were incubated with $0.5 \mathrm{McF}$ arland of $C$. violaceum 12472 at $5 \mathrm{~mL} \mathrm{LB}$, and on the next day, violacein measurement was conducted at $585 \mathrm{~nm}$ (Hamidi, 2013).

\section{Determination of "swarming" suppression}

The swarming suppression property of the methanol extract was tested by modifying the methods reported by Rashid and Kornberg (2000) and by Ugurlu (2013) P. aeruginosa PAO1 strain was grown overnight on LB agar and $50 \mu \mathrm{L}$ from the Sub-Mic or $25 \mu \mathrm{L}$ from the sub-concentration $(100 \mu \mathrm{g} / \mathrm{mL}, 50$ $\mu \mathrm{g} / \mathrm{mL}$ ) of the $C$. sativa methanol extract was added in $5 \mathrm{~mL}$ of autoclaved but not solidified LB media. Then this mixture was poured onto LB agar plates, and the agar was allowed to solidify for a while. Subsequently, $P$. aeruginosa was inoculated in the middle of the plates with a sterile toothpick and incubated at $37^{\circ} \mathrm{C}$ for $16-18$ hours. At the end of incubation, sliding movement was determined by measuring the diameter of the spread from the point of inoculation to the environment.

\section{Testing inhibition of biofilm development}

P. aeruginosa PAO1 strain was grown for $8 \mathrm{~h}$ at $37^{\circ} \mathrm{C}$ for shaking at $175 \mathrm{rpm}$ in $5 \mathrm{~mL}$ of LB medium and $1 \%$ dilution of $0.5 \mathrm{McF}$ arland, culture suspension was used for biofilm experiment. Briefly, microplate wells were filled with $125 \mu \mathrm{L}$ of LB medium, in order to $40 \mu \mathrm{L}$ of methanol extract and $35 \mu \mathrm{L}$ of $P$. aeruginosa PAO1 cells. No extract was added to the control wells, while the same amounts of bacteria and medium were added. The prepared microplates were allowed to incubate at $37^{\circ} \mathrm{C}$ for $24 \mathrm{~h}$. Subsequently, the microplates were washed three times with distilled water, and stained with $0.3 \%$ crystal violet for 15 minutes. The microplates were then washed three times with distilled water and remaining crystal violet was removed with 95\% ethanol for 15 minutes and measured on a spectrophotometer at $570 \mathrm{~nm}$ (Truchado et al., 2009; Uğurlu, 2013). Biofilm inhibition was demonstrated by averaging three repeated.

\section{Results}

\section{Antimicrobial effects of C. sativa extracts}

Methanolic extract of $C$. sativa flowers was tested against thirteen microbial strains for antibacterial activity by the agar well diffusion method, and its potential effect was determined by the presence or absence of the inhibition zones. According to results were presented in Table 2. among three gram-positive bacteria $S$. aureus was found to be the most sensitive strain with $23 \mathrm{~mm}$ inhibition zone. The extract exhibited a mild inhibition zone on B. subtilis $(12 \mathrm{~mm})$ but did not show any inhibition zone on E. faecalis. Similarly, the diameters of the zone of inhibition ranged from $7.3 \mathrm{~mm}$ to 23.0 for gram-negative bacteria. Among the 8 gramnegative bacteria $A$. haemolyticus and $P$. aeruginosa were found to be the most sensitive bacteria having the inhibition zones diameters, 23 and $12 \mathrm{~mm}$, respectively. Those zones diameters are very close to the controls. Additionally, the extract also exhibited good inhibition zones against M. smegmatis $(17 \mathrm{~mm})$ and C. violaceum $(20 \mathrm{~mm})$. Moreover, the methanol extract of $C$. sativa flowers exhibited high antifungal activity with inhibition zones ranging between $24 \mathrm{~mm}$ to $27.3 \mathrm{~mm}$ (Table 1) and MIC of $31.2 \mathrm{ug} / \mathrm{mL}$ (Table 2). The highest activity was against to $C$. albicans. 
Antimicrobial effect of the ethyl acetate extract from $C$. sativa flowers was investigated against bacteria as well as two Candida species including C. albicans and C.parapsilosis.

The extract demonstrated the antibacterial activity with inhibition zones of 17.3,10.0,15.0, 13.0,14,0 $\mathrm{mm}$ against $S$. aureus, $B$. subtilis, $K$. pneumoniae, $C$. violaceum, $M$. smegmatis, respectively. These results revealed that among three gram-positive bacteria $S$. aureus is the most sensitive strain but $M$. smegmatis was found to be the most sensitive gram-negative bacteria. Moreover, the ethyl acetate extract of $C$. sativa flowers exhibited higher antifungal activity against C.parapsilosis then $C$. albicans. with inhibition zones of $20 \mathrm{~mm}$ and $13 \mathrm{~mm}$, respectively (Table 2 ).

Ethanolic extract of $C$. sativa flowers exhibited high antibacterial activity with inhibition zones of 17.3, 20.0, $17.0 \mathrm{~mm}$ against gram-positive $S$. aureus, gram-negative $A$. haemoliyticus and $C$. violaceum, respectively. The extract exhibited moderate antimicrobial activity again $M$. smegmatis with an inhibition zone of $13.0 \mathrm{~mm}$ (Table 1) Moreover, ethanolic extract exhibited higher antifungal activity against $C$. parapsilosis then $C$. albicans. with inhibition zones of $19.0 \mathrm{~mm}$ and $13 \mathrm{~mm}$, respectively (Table 2).

None of the extracts mentioned above and DMSO (negative control) demonstrated antimicrobial activity against $E$. faecalis, E. aerogenes and $S$. typhimurium. But methanol and ethanol extracts had very weak antimicrobial effect on growth of the gram-negative $E$. coli. In terms of antimicrobial aspect, the hexonic extract of $C$. sativa flowers did not show any antimicrobial activity against microorganisms used in the present study (Table 2).

Table 2. Agar well diffusion test results $(\mathrm{mm})$

\begin{tabular}{|c|c|c|c|c|c|}
\hline \multirow{2}{*}{ Microorganisms } & \multicolumn{5}{|c|}{ Extracts } \\
\cline { 2 - 6 } & Methanol & Ethyl acetate & Ethanol & Hexane & Controls \\
\hline S. aureus & $23.33 \pm 0.47$ & $17.33 \pm 0.47$ & $17.33 \pm 0.47$ & - & $30.33 \pm 0.47$ \\
\hline B. subtilis & $12.0 \pm 0.81$ & $10.0 \pm 0$ & - & - & $22.33 \pm 0.47$ \\
\hline E. faecalis & - & - & - & - & $15.0 \pm 0.0$ \\
\hline E. coli & $7.33 \pm 0.47$ & - & $8.0 \pm 1.63$ & - & $25.0 \pm 0.0$ \\
\hline P. aeruginosa & $12.0 \pm 2.64$ & - & - & - & $13.0 \pm 0.47$ \\
\hline A. haemolyticus & $23.0 \pm 0.81$ & - & $20.0 \pm 0.0$ & - & $23.0 \pm 0.0$ \\
\hline K. pneumoniae & $7.33 \pm 0.47$ & $15.0 \pm 1.41$ & - & - & $22.0 \pm 0.0$ \\
\hline E. aerogenes & - & - & - & - & $19.0 \pm 0.47$ \\
\hline S. typhimurium & - & - & - & - & $17.0 \pm 0.0$ \\
\hline C. violaceum (ATCC12472) & $20.33 \pm 0.47$ & $13.0 \pm 0.0$ & $17.0 \pm 1.41$ & - & $30.33 \pm 0.47$ \\
\hline C. albicans & $27.33 \pm 0.47$ & $13.0 \pm 0.0$ & $13.0 \pm 0.81$ & - & $28.0 \pm 0.0$ \\
\hline C. parapsilosis & $24.0 \pm 0.0$ & $20.33 \pm 0.47$ & $19.0 \pm 0.0$ & - & $25.0 \pm 0.0$ \\
\hline M. smegmatis & $17.0 \pm 2.44$ & $14.33 \pm 0.47$ & $13.0 \pm 1.63$ & - & $24.33 \pm 0.47$ \\
\hline
\end{tabular}

The experiments were repeated three times, the values of the zone diameters were averaged, and the results are presented in Table 2. DMSO (negative control), Ampicillin, Gentamicin, Amphotericin B and Ciprofloxacin (positive controls). 6-mm zone diameter correspond to the (-) in the table.

The results of $M I C$ and $M B C$

The MIC and MBC were performed for only those methanol extracts which showed to have high antimicrobial activity by the agar well diffusion method.

Violacein inhibition results

The violacein inhibition results of the $C$. sativa extracts tested by the agar well diffusion method is presented in Table 4 and Figure 2. The results showed that methanol extract caused violacein inhibition in all Chromobacterium used. Moreover, ethyl acetate and ethanol extracts induced violacein inhibition only in $C$. 
72

violaceum ATCC 12472 strain. In order to confirm the results above, violacein inhibition of the methanol extract was also measured spectrophotometrically. As shown in Figure 3, the extract inhibited the violacein production even at very low concentrations.
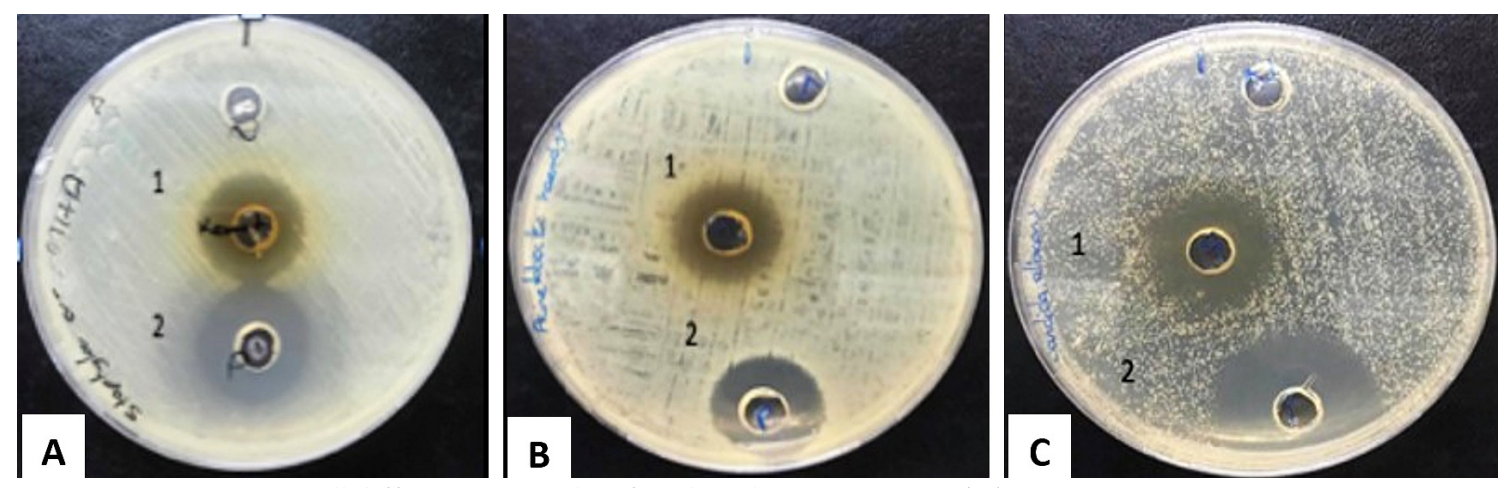

Figure 1. Agar well diffusion test results of methanol extract - A: Staphylococcus aureus ATCC 25923, A1: methanol extract, A2: Ampicillin; B: Acinetobacter haemolyticus ATCC 19002, B1: methanol extract, B2 Gentamicin; C: Candida albicans ATCC 10231, C1: methanol extract, C2: Amphotericin B

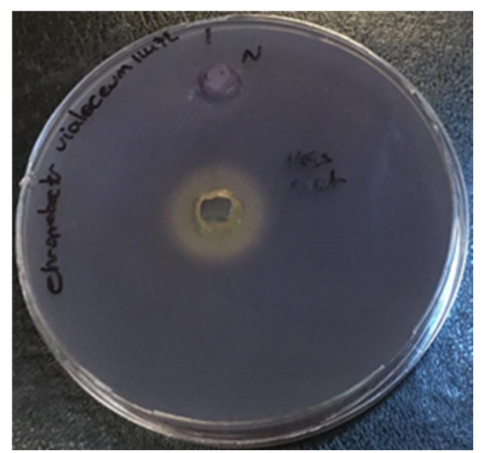

Figure 2. The effect of $C$. sativa methanol extract of C. vialoceum ATCC 12472 violacein; (a-) violacein inhibition zone



Figure 3. The effect of $C$. sativa methanol extract on the production of C. vialoceum ATCC 12472 violacein. (C.v. 12472; Only bacteria, DMSO (3\%); Bacteria and 3\% DMSO) 
Table 3. MIC and MBC results of methanol extract $(\mu \mathrm{g} / \mathrm{mL})$

\begin{tabular}{|c|c|c|}
\hline Microorganisms & MIC* $(\mu \mathrm{g} / \mathrm{mL})$ & $\mathrm{MBC}^{* *}(\mu \mathrm{g} / \mathrm{mL})$ \\
\hline S. aureus ATCC 25923 & 62.5 & 125 \\
\hline A. haemolyticus 19002ATCC & 62.5 & 125 \\
\hline M. smegmatis ATCC607 & 62.5 & 125 \\
\hline C. albicans ATCC 10231 & 31.2 & 62.5 \\
\hline C. parapsilosis ATCC22019 & 31.2 & 62.5 \\
\hline
\end{tabular}

${ }^{*}$ MIC: Minimum inhibitory concentration

${ }^{* *}$ MBC: Minimum bactericidal concentration

Summarizes the MIC and MBC values for the methanol extract of C. sativa flowers. The extract was very effective against all tested bacterial strains and displayed the MIC and MBC values of $65.5 \mu \mathrm{g} / \mathrm{mL}$ and $125 \mu \mathrm{g} / \mathrm{mL}$, respectively. Moreover, its best activity was against the yeast with the MIC and MBC values of $31.2 \mu \mathrm{g} / \mathrm{mL}$ and $62.5 \mu \mathrm{g} / \mathrm{mL}$, respectively

Table 4. Violacein inhibition results at a concentration of C. sativa of $156 \mu \mathrm{g} / \mathrm{mL}$

\begin{tabular}{|c|c|c|c|c|}
\hline \multirow{2}{*}{ Microorganisms } & \multicolumn{4}{|c|}{ Extracts } \\
\cline { 2 - 5 } & Methanol & Ethyl acetate & Ethanol & Hexane \\
\hline C. violaceum ATCC 12472 & + & + & + & - \\
\hline C. violaceum 31352 & + & - & - & - \\
\hline C. violaceum VIR07 & + & - & - & - \\
\hline C. violaceum CV026 & + & - & - & - \\
\hline
\end{tabular}

\section{"Swarming" suppression test results}

The swarming inhibition of C. sativa methanol extract in the P. aeruginosa PAO1 strain was tested, and the results are given in Table 5 and Figure 4. The results from the experiment indicated that C. sativa methanol extract inhibited the "swarming" activity of $P$. aeruginosa PAO1 at $100 \mu \mathrm{g} / \mathrm{mL}$ and $50 \mu \mathrm{g} / \mathrm{mL}$ concentrations (Table 5, Figure 4).

Table 5. "Swarming" suppression results with the $C$. sativa methanol extract $(100 / 50 \mu \mathrm{g} / \mathrm{mL})$ in the $P$. aeruginosa PAO1 strain

\begin{tabular}{|c|c|}
\hline Test plate & Diameter of zone $(\mathrm{mm})$ \\
\hline Bacteria control & 29 \\
\hline Bacteria $+100 \mu \mathrm{g} / \mathrm{mL}$ methanol extract & 9 \\
\hline Bacteria $+50 \mu \mathrm{g} / \mathrm{mL}$ methanol extract & 11 \\
\hline Bacteria $+3 \%$ DMSO & 27 \\
\hline
\end{tabular}

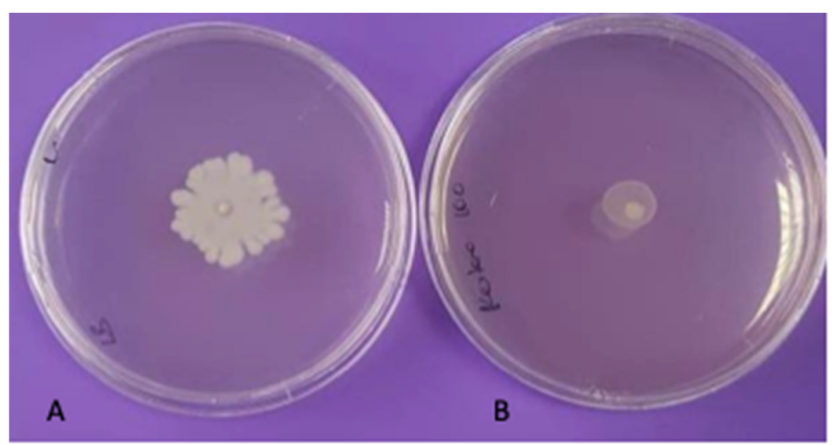

Fig. 4. "Swarming" suppression results of the $C$. sativa methanol extract $100 \mu \mathrm{g} / \mathrm{mL}$ - A-) Positive $(P$. aeruginosa PAO1) Control; B-) Bacteria $+100 \mu \mathrm{g} / \mathrm{mL}$ methanol extract 


\section{Biofilm inhibition results}

Anti-biofilm activity of the $C$. sativa methanol extract against $P$. aeruginosa PAO1 strain was tested and the results are presented in Figure 5. Compared to control, the $C$. sativa methanol extract was found to have very high biofilm suppressing activity at $100 \mu \mathrm{g} / \mathrm{mL}$ and $50 \mu \mathrm{g} / \mathrm{mL}$ concentrations.

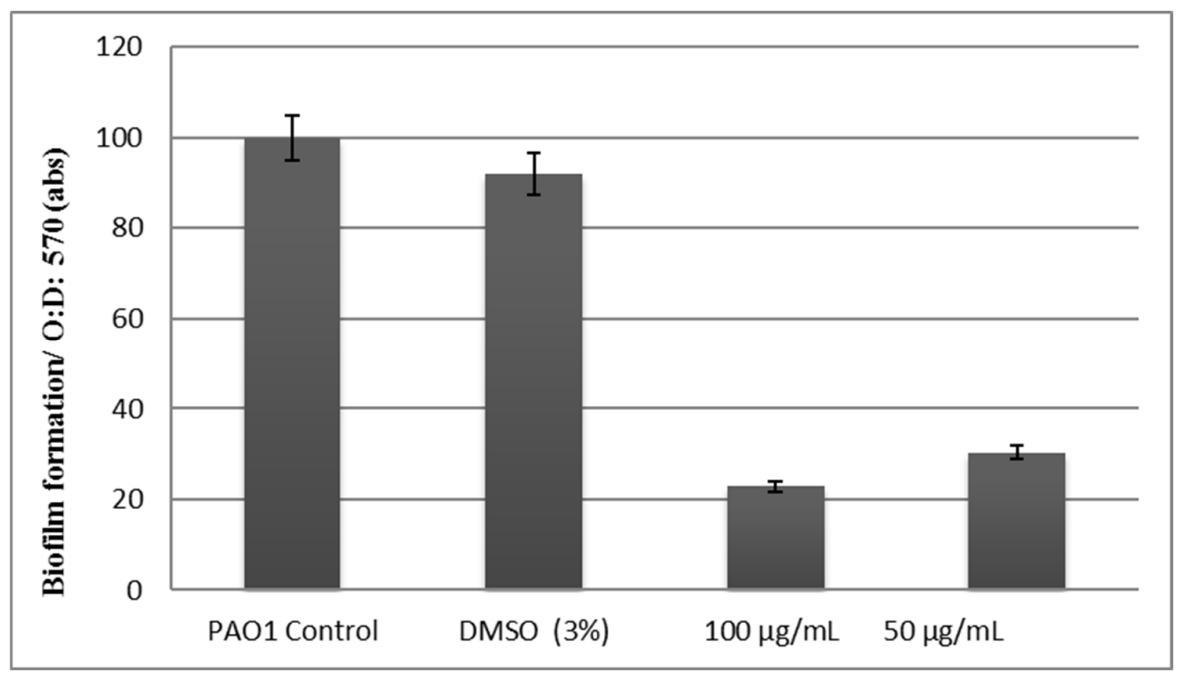

Figure 5. Biofilm results of C. sativa methanol extract. (PAO1 Control; Only Bacteria, DMSO (3\%); Bacteria and 3\% DMSO)

\section{Discussion}

Antibiotic resistance has become an important problem in almost every country, particularly in Turkey, Hence, there is an urgent needed to find alternative agents to treat resistant microorganisms. As a natural consequence of this, scientists have turned towards the medicinal plants especially in recent times. Plants have great richness in their secondary phytochemicals. More importantly, they reported that polyphenols, tannins, terpenes and alkaloids have antimicrobial activities (Cowan-Murphy, 1999).

The current study assayed the antimicrobial potential of the extracts from $C$. sativa flowers. The results obtained in this study demonstrated the methanol and ethanol extracts from $C$. sativa flowers exhibited high antibacterial effects on gram-positive $S$. aureus, and gram-negative $A$. haemolyticus. On the other hand, the ethyl acetate extract was effective on gram-positive $S$. aureus and gram-negative $K$. pneumoniae. However, no antimicrobial activities of any extract were determined on E. faecalis, E coli, E. aerogenes or $S$. typhimurium used in the study (Table 2). Avşar et al. (2016) reported that the methanol extracts obtained from the pollen grains of chestnut were completely ineffective on $K$. pneumoniae, similar to our study. On the other hand, our results indicated that ethyl acetate extract causes growth inhibition in $K$. pneumoniae which is an encapsulated bacteria and it is also one of the most important opportunist bacteria in clinic infections. More importantly, it has been shown that K. pneumoniae gains resistance worldwide (Niu et al., 2019; Kohler et al., 2017). Because of this aspect we think that our finding may be important to provided evidence that the ethyl acetate extract from $C$. sativa flowers might have some compound/compounds that may induce specific antimicrobial effect against $K$. pneumoniae.

In the literature, it has been reported that polar secondary metabolites are mostly concentrated in ethanol and methanol extracts. Hovewer, semi-polar secondary metabolites are mostly concentrated in ethyl acetate extracts (Haughton and Raman, 1998). Due to this fact that the ethyl acetate extract may have some 
different secondary metabolites in its chemical content. Therefore, those secondary metabolites may cause growth inhibition in $K$. pneumoniae. Further work is needed to identify the bioactive components that may induce antimicrobial effect against $K$. pneumoniae.

Even though, all three extracts induced varying degree of antimicrobial activity against M. smegmatis, the methanol extract of C. sativa flowers exhibited marked growth inhibition against this bacterium with MIC value $62.5 \mu \mathrm{g} / \mathrm{mL}$ (Table 3). Determination of MIC value of a plant extract has been reported as an indicator of the strong activity of that extract (Ristic et al., 2000). Although M. smegmatis is known as a non-pathogenic bacterium, but occasionally associated to human infections (Best and Best, 2009). Additionally, the fact that M. smegmatis is in the same genus as M. tuberculosis, which is known to cause a fatal disease, increases the importance of these results. The major contribution of the study to the literature may be achieved by determining the phyto-components in the extract content and their possible antimicrobial effects on other species of the genus Mycobacterium. Fokou et al. (2016) investigated antimicrobial effects of 65 extracts from 27 plant species against $M$. ulcerans and $M$. smegmatis. Their results showed that only 3 extracts had antimicrobial effects on $M$. smegmatis. These data may indicate that $M$. smegmatis is not very sensitive to secondary metabolites obtained from different plants. More importantly, it may suggest that very specific bioactive compound can induce antimicrobial activity against $M$. smegmatis.

Therefore, we think it may be important to investigate the methanol extract of chestnut flowers in terms of bioactive secondary compounds that may be significant to develop antimicrobial agent against $M$. smegmatis or against other members of Mycobacterium genus.

In our investigation, the extracts obtained from chestnut flowers have exhibited antifungal activity against $C$. albicans and C.parapsilosis species, and in particular, the methanol extract was found to have a strong antifungal effect with MIC values $31.2 \mu \mathrm{g} / \mathrm{mL}$ (Table 3). In the literature, the ability to determine the MIC value of a plant extract has been reported as an indicator of the strength of the activity of that extract (Ristic et al., 2000).

Avşar et al. (2016) found that methanol extract obtained from chestnut pollen grains had a mild antifungal effect on C. albicans and C. parapsilosis. The major difference between two studies was that they used only the pollen grains of the flowers, however, in our study, we extracted whole flowers using the methanol as a solvent. Literature studies well documented that different organs of the plants produce so many different secondary metabolites with different biological functions (Li et al., 2015). Therefore, differences in the extracts contents may determine the strong or the mild antifungal activity.

Although there is not much data showing the antimicrobial efficacy of chestnut flower with MIC values, Carocho et al. (2014) found that the extract obtained by boiling from chestnut flowers was effective on both gram-positive and gram-negative bacteria. On the other hand, the extract obtained by brewing induced higher antimicrobial effects on Aspergillus and Penicillium fungi. Those our results together, it is seen that the flower extracts of chestnut may have high antimicrobial potential and it may be affective on different groups of microorganisms.

Bacteria are social organisms and they communicate one to each other with 'quorum sensing' (QS), which is an intercellular signaling and gene regulatory mechanism used by bacteria (Quave et al., 2011). Some of those mechanisms are swarming, violacein and biofilm production. The mechanisms of QS are treated as major agents in the pathogenicity and virulence of microorganisms. In recent years, researchers have predicted that infection development of antibiotic-resistant pathogens may be controlled by inhibiting the mechanism of QS (Quave et al., 2011). Secondary metabolite production, pathogenicity, swarming, and biofilm formation are common behaviors among microorganisms in communication with signal molecules against resistance to stress. Last two decades anti-Quorum sensing activities of natural products got much attention and they reported that small molecules found in the structure of plants have a good quorum sensing suppression potential. More importantly, antimicrobial agents to be isolated from the plants can also work as quorum 
sensing inhibitor in pathogenic microorganisms (Koh et al., 2013; Bacha et al., 2016) In this respect, in the present study we investigated the effect of the C. sativa flowers extracts on the swarming, violacein and biofilm mechanisms of the QS.

To date, there is a limited amount of reports on anti-QS activity of the extracts obtained from C. sativa. Among those, Quave et al.(2011) reported ethanol extract from C. sativa inflorescence had anti-QS activity against Staphylococcus aureus (MRSA) by inhibiting $\delta$-hemolysin which is one of the products of agr (S. aureus accessory gene regulator) locus in methicillin-resistant $S$. aureus. In another study, Quave et al. (2015) screened the methanol extracts of $C$. sativa leaf for QS inhibition. Based on the results, they demonstrated that oleanene and ursene derivatives rich methanol extract showed high quorum-sensing inhibition against $S$. aureus by affecting the agr alleles. Moreover, Truchado et al. (2009) investigated the anti-QS activity of methanol and aqueous extracts obtained from chestnut honey. As a result, they found that honey, and its extracts induced $r$ anti-QS activity against gram- bacteria by inhibiting the N-Acyl-l-homoserine lactones (AHLs) which are known main bacterial signaling molecules in gram-negative bacteria.

In the present study, inhibition of violacein production was demonstrated in all Chromobacterium species. Moreover, biofilm and swarming inhibition were observed in $P$. aeruginosa PAO1 strain. All these results revealed that the C. sativa methanol extract from flowers not only show antimicrobial effect, but also induce strong anti-quorum sensing activities. It is most meaning full that this is the first work in which C. sativa methanol extracts were screened for $\mathrm{Q} S$ inhibition against Chromobacterium spp. and $P$. aeruginosa PAO1 strain.

\section{Conclusions}

Altogether, the present study revealed that $C$. sativa's flower extracts may contain various bioactive secondary substances that may induce good extent of antimicrobial properties. It would be useful to design new lead compounds against $K$. pneumoniae, M. smegmatis or against other members of Mycobacterium genus. Moreover, anti-QS activity of C. sativa's flower extracts could be used in development of novel anti-pathogenic agents since it has been reported that anti-quorum sensing compounds isolated from plants have a great potential in the fight against multidrug resistant microorganisms because of their drug-like function. To underline this aspect of the extracts as well as their active components further studies are needed.

\section{Acknowledgements}

This study was supported by the Project No: TDK-2018-959, by the BAP unit of Recep Tayyip Erdoğan University.

\section{Conflict of Interests}

The authors declare that there are no conflicts of interest related to this article

\section{References}

Avşar C, Özler H, Berber İ, Civek S (2016). Phenolic composition, antimicrobial and antioxidant activity of Castanea sativa Mill. pollen grains from Black Sea Region of Turkey. International Food Research Journal 23(4):1711-1716. 
Bacha K, Tariku Y, Gebreyesus F, Zerihun S, Mohammed A, Weiland-Bräuer N, Mulat M (2016). Antimicrobial and antiquorum sensing activities of selected medicinal plants of Ethiopia: Implication for development of potent antimicrobial agents. BMC Microbiology 16(1):139.

Best CA and Best TJ (2009). Mycobacterium smegmatis infection of the hand. International Journal of Biomedical and Advance Research Case Reports 4(2):165-166.

Carocho M, Barros L, Bento A, Santos-Buelga C, Morales P, Ferreira ICFR (2014). Castanea sativa Mill. flowers amongst the most powerful antioxidant matrices: a phytochemical approach in decoctions and infusions. Biomed Research International 2014.

Clinical and Laboratory Standards Institute (2006). Methods for dilution antimicrobial susceptibility tests for bacteria that grow aerobically approved standards. Seventh Edition Document, CLSI document M7- A7 Wayne, PA/USA.

Clinical and Laboratory Standards Institute (2008). Reference method for broth dilution antifungal susceptibility testing of yeasts; approved standard, 3rd ed., CLSI document M27-A3, Wayne, PA/USA.

Clinical and Laboratory Standards Institute (2009). Method for antifungal disk diffusion susceptibility testing of yeasts; approved guideline, 2nd ed., CLSI document M44-A2, Wayne, PA/USA.

Cowan MM (1999). Plant products as antimicrobial agents. Clinical Microbiology Reviews 12 (4):564-582.

Denev P, Kratchanova M, Ciz M, Lojek A, Vasicek O, Nedelcheva P, ... Vojtek L (2014). Biological activities of selected polyphenol-rich fruits related to immunity and gastrointestinal health. Food Chemistry 157:37-44.

Fokou VT, Twum Kissi AD, Manu Yeboah D (2016). In vitro activity of selected west African medicinal plants against Mycobacterium ulcerans disease Patrick. Molecules 21(4):445.

Hamidi S (2013). Bazı Sentetik Kimyasal Maddelerin ve Doğal Ekstraktların Antimikrobiyal ve Anti- quorum sensing aktivitelerinin Araştırılması. MSc Dissertation, Karadeniz Technical University, Trabzon.

Hao JJ, Liu H, Donis-Gonzalez IR, Lu HX (2012). Antimicrobial activity of chestnut extracts for potential use in managing soilborne plant pathogens. Plant Disease 96(3):354-360.

Houghton PJ, Raman A (1998). Laboratory handbook for the fractionation of natural extracts. Department of Pharmacy King's College London UK pp 14-21.

Ketenoğlu O, Tug GN, Kurt L (2010). An ecological and syntaxonomical overview of Castanea sativa and a new association in Turkey. Journal of Environmental Biology 31(1-2):81-6.

Koh CL, Sam CK, Yin WF, Tan LY, Krishnan T, Chong YM, Chan KG (2013). Plant-derived natural products as sources of anti-quorum sensing compounds. Sensors 13(5):6217-6228.

Koh KH, Tham FY (2011). Screening of traditional Chinese medicinal plants for quorum-sensing inhibitors activity. Journal of Microbiology Immunology and Infection. 44(2):144-148.

Kohler PP, Volling C, Green K, Uleryk EM, Shah PS, McGeer A (2017). Carbapenem resistance, initial antibiotic therapy, and mortality in Klebsiella pneumoniae bacteremia: a systematic review and meta-analysis. Infection Control and Hospital Epidemiology 38(11):1319-1328.

Kolaylı S, Can Z, Yıldız O, Şahin H, Alpay Karaoğlu Ş (2016). A comparative study of the antihyaluronidase, antiurease, antioxidant, antimicrobial and physicochemical properties of different unifloral degrees of chestnut (Castanea sativa Mill.) honeys. Journal of Enzyme Inhibition and Medicinal chemistry 31(3):96-104.

Li CF, Zhu Y, Yu Y (2015). Global transcriptome and gene regulation network for secondary metabolite biosynthesis of tea plant (Camellia sinensis). BMC Genomics 16(1):560.

Lim TK (2013). Edible medicinal and non-medicinal plants. Fruits. Academic Press (6th ed), New York.

McLean RJC, Pierson LS, Fuquac C (2004). A simple screening protocol for the identification of quorum signal antagonist. Journal of Microbiological Methods 58(3):351-360.

Mcloone P, Warnock M, Fyfe L (2015). Honey: a realistic antimicrobial for disorders of the skin. Journal of Microbiology, Immunology and Infection 49(2):161-167.

Murray PR, Baron EJ, Pfaller MA, Jorgensen JH, Yolken RH (2009). Manual of clinical microbiology. Academic Press ( 9 th ed), Washington.

National Committee for Clinical Laboratory Standart (1999). Methods for determining bacterial activity of antimicrobial agentes; Approved Guideline. NCCLS, M26-A,19, Willanova, PA/USA.

Newman DJ and Cragg GM (2012). Natural products as sources of new drugs over the 30 years from 1981 to 2010. Journal of Natural Products 75(3):311-335. 
Niu H, Zhang W, Wei L, Liu H, Zhao C, Liu M, Geng J (2019). Rapid nanopore assay for carbapenem-resistant Klebsiella pneumonia. Frontiers Microbiology 10:1672.

Pacheco-Ordaz R, Wall-Medrano A, Goni MG, Ramos-Clamont-Montfort G, Ayala Zavala JF, Gonzzalez-Aguilar GA (2018). Effect of phenolic compounds on the growth of selected probiotic and pathogenic bacteria. Letters in Applied Microbiology 66(1):25-31.

Paul GG, Gordon MC, David JN (2010). Plant natural products in anticancer drug discovery. Current Organic Chemistry 14(16):1781-1791.

Pereira C, Barros L, Carvalho AM, Ferreira ICFR (2013). Use of UFLC-PDA for the analysis of organic acids in thirtyfive species of food and medicinal plants. Food Analytical Methods 6(5):1337-1344.

Quave LC, Lyles TJ, Kavanaugh SJ, Nelson K, Parlet CP, Crosby HA, ... Horswill AR (2015). Castanea sativa (European chestnut) leaf extracts rich in ursene and oleanene derivatives block Staphylococcus aureus virulence and pathogenesis without detectable resistance. Plos One 10(8):e0136486.

Quave LC, Plano RWL, Bennett CB (2011). Quorum sensing inhibitors for Staphylococcus aureus from Italian medicinal plants. Planta Medica 77(2):188-195.

Rashid MH, Kornberg A (2000). Inorganic polyphosphate is needed for swimming, swarming, and twitching motilities of Pseudomonas aeruginosa. Proceedings of the National Academy Sciences of the United States of America 97(9):4885-4890.

Ristic MD, Duletic-Lausevic S, Knezevic-Vukcevic J, Marin PD, Simic D, Vukojevic J, ... Vajs V (2000). Antimicrobial activity of essential oils and ethanol extract of Phlomis fruticosa L.(Lamiaceae). Phytotheraphy Research 14(4):267-271.

Ronsisvalle S, Lissandrello E, Fuochi V, Petronio GP, Straquadanio C, Crascì L, ... Furneri PM (2017). Antioxidant and antimicrobial properties of Casteanea sativa Miller chestnut honey produced on Mount Etna (Sicily). Natural Product Research 33(6):843-850.

Solanki R, Nagori BP (2012). New method for extracting phytoconstituents from plants. International Journal of Biomedical and Advance Research 3(10):770-774.

Torres M, Romero M, Prado S, Dubert J, Tahrioui A, Otero A, Llamas I (2013). N-acyl homoserine lactone degrading bacteria isolated from hatchery bivalvelarval cultures. Microbiological Research 168(9):547-554.

Truchado P, Gil-Izqierdo A, Tomas-Barberan F, Allenda A (2009). Inhibition by chenut honey of N-Acyl-L-homoserine lactones and biofilm formation in Erwinia carotovora, Yersinia enterocolitica and Aeromonas hydrophila. Journal of Agricultural and Food Chemistry 57(23):11186-11193.

Uğurlu A (2013). Pseudomonas aeruginosa Suşlarında Çevreyi Algılama Sistemine Fenolik Maddelerin Etkisinin Araştırılması. Master thesis, Marmara University. İstanbul.

Vasconcelos MCBM, Bennett RN, Rosa EAS, Ferreira-Cardoso JV (2010). Composition of European chestnut (Castanea sativa Mill.) and association with health effects: fresh and processed products. Journal of the Science Food and Agriculture 90(10):1578-1589.

Woods GL, Brown-Elliott BA, Desmond EP, Hall GS, Heifets L, Pfyffer GE, ... Witebsky FG (2003). Susceptibility testing of mycobacteria, nocardiae, and other aerobic actinomycetes. Approved Standard. NCCLS Doc. M24-A, 18, pp 20-31.

Yaldız G, Yüksel T, Şekeroğlu N (2010). Rize ili florasında bulunan tıbbi ve aromatik bitkiler ve kullanım alanları [Medicinal and aromatic plants in the flora of Rize province and their usage areas]. 20-22 May 2010, III Ulusal Karadeniz Ormancillk Kongresi 3:1100-1114.

Zitkovic J, Zekovic Z, Mujic I (2010). Scavenging capacity of superoxide radical and screening of antimicrobial activity of Castanea sativa Mill. extracts. Czech Journal of Food Sciences 28(1):61-68.
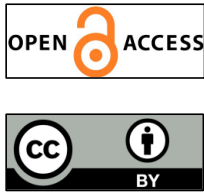

The journal offers free, immediate, and unrestricted access to peer-reviewed research and scholarly work. Users are allowed to read, download, copy, distribute, print, search, or link to the full texts of the articles, or use them for any other lawful purpose, without asking prior permission from the publisher or the author.

License - Papers published in Notulae Botanicae Horti Agrobotanici Cluj-Napoca are Open-Access, distributed under the terms and conditions of the Creative Commons Attribution (CC BY) License.

(c) Articles by the authors; UASVM, Cluj-Napoca, Romania. The journal allows the author(s) to hold the copyright/to retain publishing rights without restriction. 